\title{
Quando uma professora de Matemática do CAP-UERJ resolve produzir escritas de si: autoformação?
}

Gabriela Félix Brião*

\begin{abstract}
Resumo
Este trabalho é um breve relato sobre uma pesquisa (auto)biográfica de uma professora de matemática em busca de compreensão de suas práticas e formação docentes. De forma a tentar descortinar práticas ora insubordinadas criativas, ora contraditórias, com suas próprias crenças sobre o que é a matemática, a autora tenta transportar o leitor para um lugar de reflexão, por vezes, desconfortável. De todo modo, é desta forma que a jornada se apresenta, em meio a diversos conceitos da Educação Matemática, mas também se aproximando da literatura. Como contribuição direta destes escritos podemos citar a produção de conhecimento ao redimensionar saberes implícitos, sobre como um professor de matemática vê as suas práticas e formação, o catapultando para a visibilidade no que há de mais corriqueiro no seu dia a dia profissional, sua prática em sala de aula.
\end{abstract}

Palavras-chave: pesquisa (auto)biográfica, formação de professores, colégio de aplicação, insubordinação criativa.

When a teacher of mathematics of CAP-UERJ produces self-writings: self-formation?

\begin{abstract}
This work is a brief report about a (auto)biographical inquiry of a mathematics teacher in search of an understanding of her practices and teacher training. In order to try to uncover creative insubordinate or sometimes contradictory practices, with her own beliefs about what mathematics is, the author tries to convey the reader to a place of reflection that is sometimes uncomfortable. In any case, this is how the journey presents itself, in the midst of several concepts of Mathematics Education, but also with an approach to literature. As a direct contribution of these writings, we can cite the production of knowledge by redimensioning implicit knowledge, about how a mathematics teacher sees her practices and training, catapulting to the visibility of what is most common in herday-to-day professional life, her practice in classroom.
\end{abstract}

Keywords: (auto)biographicalinquiry, teacher training, lab school, creative insubordination.

* Graduada em Licenciatura Plena em Matemática pela Universidade do Estado do Rio de Janeiro (UERJ). Mestre em Matemática pela Associação Instituto Nacional de Matemática Pura e Aplicada (IMPA). Doutora em Educação Matemática - UNESP/Rio Claro, com estágio sanduíche de um ano na Miami University, Oxford, OH, USA. Professora assistente da Universidade do Estado do Rio de Janeiro. E-mail: gabriela.felix@gmail.com. 


\section{Isto é o que me move}

Sou uma professora de Matemática de um Instituto de Aplicação que abriga um Colégio de Aplicação. Já participo do cotidiano do Instituto há mais de quinze anos, contando o tempo como estagiária, quando estudante de graduação, e também como professora. "O que faço por lá?" Pergunta simples, faço tudo o que me é exigido como professora universitária de uma grande universidade brasileira, contudo há um diferencial: dou aulas tanto no ensino básico quanto no superior, na formação de professores. Além disso, oriento trabalhos científicos, trabalho na comunidade por meio de projetos de extensão, pesquiso, supervisiono estágios de futuros docentes e auxilio questôes administrativas.

Estou inserida em um modelo de formação inovador, que oferece ao licenciando a oportunidade de lidar com o professor universitário dos seus estágios e práticas docentes, que também atua na sala de aula da escola básica. Essa mesma sala de aula onde o futuro professor irá estagiar. Falo e pratico, contudo, com isto não estou dizendo que o faço de forma coerente. Ou seja, participo da formação prática e teórica deste artista-professor (GÓMEZ, 1995). Esta é a maior riqueza desse Instituto de Aplicação, que ao abrigar um Colégio de Aplicação, torna-se um espaço único de discussão de práticas docentes que ocorrem na sala de aula do segmento básico de ensino, o palco principal da atuação desse futuro docente que ajudo a formar.

Por conta do que foi mencionado anteriormente, sinto que possuo uma visão panorâmica do processo formador pelo qual formo e sou formada. Essa visão ampliada da profissão docente trouxe-me uma enorme vontade de escrever sobre as experiências de formação matemática e pedagógica. Surgiu, assim, um desejo inconsequente de narrar-me com o que tenho em mãos: experiências singulares em razão do contexto no qual meus estudantes-professores, estudantes-escolares e eu, estudante-pesquisadora, nos inserimos. Ao que vale adicionar que "o magistério é uma atividade não-rotineira, conduzida de forma colaborativa” (POLETTINI, 1999, p. 248), o que certamente diz muito sobre o contexto no qual a minha narrativa (auto)biográfica (PASSEGGI, 2010) surge como um movimento formativo, assim como de pesquisa da prática do professor. Uma verdadeira aventura autobiográfica.

Diante dessa escolha inusitada de contar-me - poderiam dizer alguns - resolvi seguir o instinto que me dizia que com esta opção feita, 
o caminho precisaria ser trilhado e apreciado, não importando tanto para onde gostaria de ir ao final - o objetivo se subjetivava. Pois é, quando traçamos um objetivo, muitas vezes achamos que o caminho é um só e que através dele podemos chegar onde queremos. Essa é uma ilusáo interessante, pois muitas possibilidades se abrem quando decidimos empreender nossa jornada rumo a novas paragens. Assim, ao nos propormos a seguir em uma jornada narrativa, o que parece é que adentramos por um bosque, este como "uma metáfora para o texto narrativo", pois "é um jardim de caminhos que se bifurcam" (ECO, 1994, p. 12). Aqui escritor e leitor se veem diante de uma trajetória repleta de possibilidades. O narrador, por motivos óbvios, pode contar uma mesma história sob inúmeras perspectivas. Embora a documentaçáo de minhas escolhas durante o percurso tenha caracterizado a minha pesquisa como científica, o leitor precisa preencher as lacunas deixadas, com suas próprias experiências, procurando não sufocar silêncios. Assim, temos nesse momento, um cúmplice do narrador, pois "a linguagem não reflete a realidade, a constrói” (LARROSA, 2004, p. 14, tradução nossa).

E onde gostaria de chegar ao final da minha caminhada? Em um lugar onde eu pudesse compreender cada vez mais as minhas práticas, libertando-as de lugares que não são meus e colocando-me como protagonista de minhas ações e de minha formação. Dessa forma, quero me ver em uma aula de matemática, com as crianças sendo respeitadas pela matemática que sabem. Não, não quero julgá-las buscando o que não sabem! Isso é fácil demais e é o que já está posto à mesa! Quero correr atrás da riqueza do que já sabem, constituída através de suas construções de mundo, de sua presença! (FREIRE, 1996).

Pensando como formadora de professores, foi por empreender a busca por um processo formativo - que trouxesse a matemática de forma mais humanizada, como produção humana e não como um filtro social ou como algo tấo divino que pertença ao mundo das ideias - que resolvi me engajar ainda com mais afinco nesta jornada de "contaçóes" de histórias. Afinal, se desse certo comigo, quem sabe eu poderia pensar nesta forma de fazer pesquisa e de reflexão também para os futuros professores, empoderando-os em suas identidades docentes em construção.

Não vá pensando que este é um movimento narrativo tranquilo para mim, que sou uma professora de matemática. Meu arsenal de escrita é ligeiramente limitado. As equações e teoremas não me estimularam a escrever grandes narrativas. Mas cada um teima com o que pode. Eu teimei em 
também ser uma leitora voraz, o que talvez explique essa coragem de tentar escrever narrativas de mim.

Conforme vou escrevendo o que propus, percebo que outras escolhas poderiam ser feitas, mais caminhos no meu bosque, e me sinto tal e qual Clarice Lispector em sua "A quinta história":

Esta história poderia chamar-se "As Estátuas". Outro nome possível é "O Assassinato". E também "Como Matar Baratas". Farei então pelo menos três histórias, verdadeiras, porque nenhuma delas mente a outra. Embora uma única, seriam mil e uma, se mil e uma noites me dessem. (LISPECTOR, 1977, grifo do autor).

Observo que preciso da relação com "o outro" e comigo mesma para seguir por algum dos inúmeros caminhos narrativos que disponho. E é nessa relação que construo junto ao meu leitor ideal, assim como com meus companheiros de jornada (pessoas que leram versóes de meu "romance de formação", interagindo com o texto. As contribuiçóes desses colaboradores foram imprescindíveis para que o trabalho tivesse um caráter formador), que ouso refletir sobre a minha prática e formação de uma forma mais aprofundada. Mais consciente.

[...] a noção de consciência histórica é fundamental para compreendermos a experiência em formação. Entendemos que ela só se justifica se permitir à pessoa que narra compreender a historicidade de suas aprendizagens e construir uma imagem de si como sujeito histórico, situado em seu tempo. (PASSEGGI, 2011, p. 149).

Nesta pesquisa (auto)biográfica, a experiência é fundamental. Como Larrosa (2004) denuncia, é essa experiência cada vez mais rara por conta dos excessos de nosso tempo. O professor consciente de seu papel social e histórico é um sujeito da experiência, pois é "um sujeito ex-posto" (LARROSA, 2004, p. 161) em sua arte, vulnerável em seu posicionamento no mundo. Sendo assim, parto do princípio de que o professor é um sujeito da experiência.

Sou uma professora de matemática adepta a práticas de insubordinação criativa (BRIÃO, 2015; D’AMBROSIO; LOPES, 2015) quando me vejo uma professora que pede para os alunos produzirem suas próprias avaliaçóes; quando valorizo as matemáticas viáveis do aluno em sala - respeitando seus momentos de aprendizagem -; quando ouso trazer uma rou- 
pagem relacional (que depende da relação que floresce com o estudante) ao conteúdo; quando a minha voz na sala é somente mais uma voz; quando me recuso a acreditar que um estudante não tem mais jeito e ajo a seu favor. Práticas que surgem de forma criativa para desafiar o que está posto e com o qual o professor não concorda, agindo em favor do que acredita ser melhor para a aprendizagem dos estudantes. Estas são formas de experienciar a docência.

Não gosto muito das mesmices cotidianas que seguem por caminhos previsíveis, a docência nada tem a ver com rotina. Difícil mesmo é empoderar os estudantes naquilo que sabem e com eles se chegar a algum outro lugar. Não, esse lugar não é um abatedouro de sonhos! Este lugar é um "super perfeccionador de asas"! Lugar de aprendizagens! Ambos sabemos que esta forma de praticar o ensino da matemática está longe do "ideário" que existe, em que o professor somente impóe sua forma de conhecer, em detrimento da riqueza de inteligências existentes em uma sala de aula. E estou falando somente de uma! Imagine quantas salas de aula estáo oferecendo aulas de Matemática recheadas de uma matemática régia, distante das ideias criativas dos estudantes sobre matemática.

Falo do ponto de vista de uma professora construtivista (D'AMBROSIO; STEFFE, 1994), pronta para valorizar o conhecimento de meus alunos, criando modelos de suas matemáticas viáveis e legítimas. Para de tais conjecturas sobre como o aluno entende determinado assunto, sob seu ponto de vista, desafiá-lo a novas formas de conhecer.

Veja bem, não estou dizendo aqui que todos nós somos capazes, sem muito esforço, de ascender a um conhecimento que se distancie do senso comum, das observaçóes sensoriais, e chegue a um conhecimento científico, mais estruturado, refletido em detalhes. Estou afirmando que todos nós seguimos certas linhas de raciocínio matemático. Portanto, o importante para a alfabetização matemática é justamente provocar este raciocínio a transcender do ponto em que está, sempre valorizando o que o educando produz.

A partir dessa metodologia de acreditar na produção "do outro", há uma escuta hermenêutica do que o aluno tem a dizer, dando razáo aos estudantes da educação básica, ouvindo, acreditando, cuidando, suspendendo a dúvida (D’AMBROSIO; KASTBERG, 2012). Esse é um processo educativo ético. 


\section{Alguns achados preciosos}

Estou escrevendo uma tese de doutorado sobre esta minha jornada narrativa em busca de redenção, ops!', autoformação. Mas não quero aqui fazer uma análise do movimento do meu discurso. Busco aventurar-me por caminhos novos, que se configuram neste artigo como relatos de uma professora de matemática e formadora que vê a sua docência com contradições e insubordinaçōes. E assim, conforme vou escrevendo, minha identidade docente vai se mostrando cada vez mais nítida para mim: uma professora reflexiva, insubordinada criativa, contraditória, múltipla.

Afinal, o que significa, hoje, solicitar, ou entregar, aos professores a tarefa de narrar sua história de vida e ressignificar suas experiências profissionais e intelectuais? Somente na perspectiva de que a reflexividade autobiográfica propicia a quem narra a possibilidade de abertura para novas experiência é que podemos acatar a ideia da experiência em formação no seu duplo sentido: o de prática formadora e o de reelaboraçáo permanente. As metáforas de Zygmunt Bauman - Amor líquido, Medo líquido, Modernidade líquida - autorizam-nos a pensar em experiência líquida como modo de concebê-la, em contínua formação e em contraposição a qual - quer ideia de rigidez, de cristalização ou de enclausuramento do sujeito na experiência vivida e ressignificada. Também, temos de ter o cuidado de evitar o retorno à concepção de enclausuramento $\mathrm{da}$ experiência no sujeito. A fluidez da experiência afiança a relativa invenção do ser. (PASSEGGI, 2011, p. 154, grifo nosso)

Esse professor reflexivo (ZEICHNER, 2008) que tento ser e com o objetivo de contribuir para a formação de outros professores, me traz um vislumbre de potência de transformação de práticas. De meu ponto de vista, que práticas? Práticas que se distanciam do fazer mais do mesmo e se tornam práticas autorais, despidas de preconceitos sobre o como ensinar matemática. Práticas impregnadas de ideias que pipocam na cabeça de um professor que constrói a sua docência em colaboração com o estudante. Esse professor é aquele que pratica o ensino de acordo com uma visão mais ampla de mundo - aquele que deseja viver - e que toma as rédeas de sua própria formação. Há, contudo, um movimento contrário, segundo o qual quanto mais eu clame por autenticidades em minhas práticas, menos eu saiba quem sou. Assim, existe um reinventar-se contínuo. Por isso, a jornada narrativa não cessa, ficam entremeios, com pontos finais simbólicos. Afinal, lecionar 
é uma prática pessoal, baseada na experiência do docente. Se há a experiência (LARROSA, 2002), há sempre uma inauguração em curso. Estou falando aqui de uma aprendizagem biográfica, na qual minhas experiências em formação propiciadas pela reflexividade autobiográfica mais uma vez me (trans)formam, em um processo contínuo de (re)invenção de meus eus-professores (DAY et al., 2006).

Dessa forma, encontrei autoformação nas narrativas, pois me tornei cada vez mais consciente de certos equívocos em minha "formação oficial" dentro do ambiente escolar e universitário, problematizando-os. As escritas de si, nesse sentido, se mostram um meio interessante para valorizar memórias de maneira crítica, inclusive construindo memórias alternativas, ou seja, contramemórias que libertam o sujeito da experiência de certos movimentos de padronização (BUENO et al., 1993).

As minhas insubordinaçóes criativas como professora de matemática surgem, portanto, como autoinsubordinaçóes criativas, termo cunhado durante a viagem narrativa a essas experiências formativas anteriores - que se encontram em minha memória - e impostas, e que não correspondem à maneira matemática como me coloco no mundo. Esta é uma das teorias educacionais vivas com as quais me deparei durante a busca por compreender as minhas práticas e formação, um ciclo explicado por Whitehead (1989).

Outra observação com a qual me deparei foi que me encontrei em uma contradição tremenda, quando percebi que ensino a matemática de uma forma, mas que ensino a ensinar a matemática de outra. Percebi que existia uma multiplicidade de professoras em mim, muitas vezes contraditórias. Pois bem, já falei um pouco sobre como vejo a matemática na escola. Agora, com os futuros professores, como ser uma professora construtivista também? Como não exigir que eles sigam os meus modos de ser professora, transformando-os em alguma outra coisa e silenciando suas identidades? Eu oferecia a possibilidade de o professor ser construtivista, mas minha abordagem com ele nada tinha a ver com o construtivismo. Eu estava em uma contradição viva (WHITEHEAD, 1989). Viva, pois vivia em minha prática!

Diante de tal dilema, Beatriz D’Ambrosio e Signe Kastberg (2012) trazem que para ser um formador construtivista, o professor deve criar modelos dos "eus-professores" desses futuros profissionais. Nesse contexto, o ouvir acreditando, com respeito às concepçóes do licenciando, se torna fundamental. O que acaba formando uma pedagogia da identidade (JENLINK, 2014). 
Ao colocar como legítimas as concepçóes de ensino que surgem no ambiente de formação, o formador tem a possibilidade de desafiar essas ideias, criando episódios de aprendizagem construtivistas.

Formadores que compreendem que a formação das identidades dos estudantes são individuais também compreendem a formação de suas próprias identidades. Neste sentido, formadores de professores devem praticar uma pedagogia da identidade que criticamente examina as consequências que discursos e práticas dominantes têm tido na criação de suas próprias vidas e nas vidas de seus estudantes. (JENLINK, 2014, p. 257, tradução nossa).

A verdade é que achei mais "eus-professores" do que pensava que poderia encontrar. Até o momento em minha pesquisa, observo que um professor de matemática pode mobilizar diversos "eus-professores" em sua sala e quanto mais liberdade ele tiver para se movimentar entre esses "eus", mais autoral será a sua prática. Eu não autorizava o licenciando a expor as suas formas de conceber a docência. De forma autoritária, eu fazia o que achava que seria melhor para as crianças, me contradizendo vivamente.

Podemos ficar só na prática do reproduzir o que outros fizeram, como se apresenta em livros didáticos, por exemplo, ou podemos ousar caminhar por outras direçóes. Essa liberdade de se compreender como um produtor de conhecimento junto aos estudantes, que entendo como agência (CYRINO; OLIVEIRA, 2011), torna o professor autoral, justamente por praticar um ensino em relaçáo com o educando. Esse professor realmente se relaciona com os estudantes, disponibilizando novas possibilidades de aprendizagem para todos os envolvidos no contexto educativo.

Para fechar esta seção, gostaria de observar que faço um relato de um trabalho com uma forte característica ficcional, pois náo fala do lugar de onde a academia espera. Caracteriza-se pela sua resistência, uma não adequação, um posicionamento epistemopolítico (PASSEGGI, 2010) dentro das pesquisas em educação. Uma insubordinação criativa em pesquisa:

Aventurar-se a pesquisar é explorar o desconhecido, é instigar-se por possíveis mistérios, é mergulhar em ondas imprevisíveis! Investigar é buscar o prazer da descoberta, do confronto com o novo e a liberdade de trilhar caminhos que ainda não foram percorridos ou de alterar o trajeto durante o percurso. Sáo açóes assim que permitem a quem pesquisa a ousadia criativa. (D'AMBROSIO; LOPES, 2015b, p. 12). 


\section{Será que cheguei onde eu era esperada?}

Já cheguei a algum lugar? Tinha um pote de ouro por lá me esperando? Será que este lugar algum dia existiu? Por que quando se chega já não se é outro? Como reconhecer com os novos olhos que ganhei, após passar por esta experiência narrativa, se era por lá que queríamos estar mesmo? Espero não te desapontar, mas o lugar onde estou agora não é exatamente o que eu esperava de todo. É outra coisa. Acabei me tornando outra durante o processo. Afinal, "a narrativa diz respeito aos dilemas, às estradas por onde se caminha; mais aos nossos passos do que ao lugar aonde se chega" (PAULO, 2016, p. 95), em concordância com o pensamento de Jerome Bruner.

Compreendi que quando me utilizo da literatura para expor algum contexto matemático, este eu-professor está diretamente relacionado ao meu eu-leitor, ou quando discuto a matemática de outros povos, outras formas de compreender as "ticas" do matema, a etnomatemática (D'AMBROSIO, 2009), sinto que estou mobilizando um eu-professor relacionado ao meu "eu-viajante". De todo modo, tento criar um ambiente acolhedor em sala, de respeito e carinho para com o próximo. É neste ambiente que mostro aos estudantes que podemos repensar as nossas atitudes em uma aula de matemática, utilizando frases mágicas tais como: conjecturo que, a sua hipótese é, acho que devemos refletir mais sobre isso, tais como me inspirou Magdalene Lampert (1990). Um fluxo contínuo e crítico de ideias.

Os escritos autobiográficos propiciam ao professor, que se constitui em um sujeito da experiência, uma oportunidade de explorar os seus saberes implícitos. Esse professor valoriza-se ao colocar no papel suas experiências formativas, e em formação. Quando, em minha pesquisa doutoral, relato sobre a multiplicidade de formas de me encontrar professora, ou quando narro as dificuldades em lidar com "o outro", trago preciosos tesouros que me constituem mais uma vez professora. O que naturalmente faz parte de meus processos identitários.

De onde falo? De onde minha substância como professora aflora? O que é a matemática para mim? Para começar, não é a matemática e, sim, as matemáticas. Produçóes humanas que tem a ver com uma forma singular de compreender o mundo em que vivemos. Só para citar algumas 
- as mais próximas de meu cotidiano -, temos a matemática escolar, a matemática dos matemáticos, a matemática do cotidiano (CIVIL, 2002).

Faz parte do meu trabalho como professora de Matemática, criar ambientes de aprendizagem que apresentem outras formas matemáticas de se estar no mundo. Infelizmente, temo que diversos colegas de profissão mantenham-se somente na zona do exercício dentro de um contexto matemático, mas existem outros ambientes possíveis (SKOVSMOSE, 2000). Nítido está para mim, que devo sempre tentar esgarçar zonas de conforto e me expor, vulnerável, a toda uma gama de possíveis incômodos que caracterizam o aprender. Se o desejo é que alguém aprenda algo, este "aprendente" deve ser provocado para tal.

Pude constatar que a escrita de si, ou podemos chamá-la de narrativa autobiográfica, tem um potencial riquíssimo na formação de um professor, seja esta inicial ou em carreira. Ao narrar-me, vou me constituindo cada vez mais como a docente que sou, com minhas aulas autorais, meus processos autoformativos, minhas buscas incessantes por metamorfosear-me em outra coisa. Talvez em uma "boa professora" de Matemática.

A autoformação foi uma constante durante o trabalho narrativo, uma vez que uma professora constituiu-se durante o contar-se. Essa certa professora Gabriela, que é multiplicidade, percebeu uma vez mais que não somos nada sem o outro. Que o desprezo pelos saberes do outro é algo inaceitável, principalmente em uma sala de aula. Com contos, novos dicionários, rabiscos e trocas com companheiros de jornada, essas professoras Gabrielas perceberam-se fadadas a provocar aprendizagens para si e para o outro.

Não busco com o meu processo narrativo uma prescrição para a formação do professor de Matemática. Busco uma saída para a minha própria formação que pode, de quebra, trazer novas ideias para a formação de outros professores, empoderando-o a seguir o seu caminho a passos firmes. E assim vou (re)construindo a minha identidade profissional, a partir de minhas narrativas.

Fecho, então, com uma fala de Contardo Calligaris, ${ }^{1}$ "nossa identidade é narrativa, ou seja, nossa experiência não descreve, não reflete, mas institui, cria, inventa, os lugares de quem dança conosco e o nosso lugar na dança”.

1 Contardo Calligaris, psicanalista e cronista italiano radicado no Brasil, durante palestra no Seminário Fronteiras do Pensamento, em Porto Alegre, em 4 de agosto de 2008. 


\section{Referências}

BRIÃO, G. F. Algumas insubordinaçôes criativas presentes na prática de uma professora de matemática. In: D’AMBROSIO, B.; LOPES, C. E. (Org.). Ousadias criativas nas práticas de educadores matemáticos. Campinas: Mercado de Letras, 2015. p. 87-102.

BUENO, B. O.; SOUSA, C. P. de; CATANI, D. B.; SOUZA, M. C. C. C. de. Docência, memória e gênero: estudos alternativos sobre a formação de professores. Psicologia USP, São Paulo, v. 4, n. 1/2, p. 299-318, 1993.

CIVIL, M. Everyday mathematics, mathematicians' mathematics, and school mathematics: can we bring them together? In: CYRINO, M. C. C.; OLIVEIRA, H. M. A formação inicial de professores de matemática em Portugal e no Brasil: narrativas de vulnerabilidade e agência. Interacçôes, Lisboa, n. 18, p. 104-130, 2011.

D’AMBROSIO, B. S.; LOPES, C. E. Insubordinação criativa: um convite à reinvenção do educador matemático. Bolema, Rio Claro, v. 29, n. 51, p. 1-17, 2015a.

D’AMBROSIO, B. S.; LOPES, C. E. (Org.). Vertentes da subversão na produção cientifica em educação matemática. Campinas: Mercado de Letras, 2015b.

D'AMBROSIO, B. S.; KASTBERG, S. Giving reason to prospective mathematics teachers. For the Learning of Mathematics, Kingston, v. 32, n. 3, p. 22-27, 2012.

D’AMBROSIO, B. S.; STEFFE, L. P. O ensino construtivista. Em Aberto, Brasília, v. 14, n. 62, p. 23-32, 1994.

D’AMBROSIO, U. Educação matemática: da teoria à prática. 17. ed. Campinas: Papirus, 2009.

DAY, C.; KINGSTON, A.; STOBART, G.; SAMMONS, P. The personal and professional selves of teachers: stable and unstable identities. British Educational Research Journal, Wales, v. 32, n. 4, p. 601-616, 2006.

ECO, U. Seis passeios pelos bosques da fição. São Paulo: Companhia das Letras, 1994. 
FREIRE, P. Pedagogia da autonomia: saberes necessários à prática educativa. 34. ed. São Paulo: Paz e Terra, 1996.

GÓMEZ, A. P. O pensamento prático do professor: a formação do professor como profissional reflexivo. In: NÓVOA, A (Org.). Os professores e a sua formação. 2. ed. Lisboa: Instituto de Inovação Educacional, 1995. p. 93114 ,

JENLINK, P. M. Teacher Identity and the struggle for recognition: meeting the challenges of a diverse society. Lanham: Rowman \& Littlefield Education, 2014.

LAMPERT, M. When the problem is not the question and the solution is not the answer: mathematical knowing and teaching. American Educational Research Journal, Thousand Oaks, v. 27, n. 1, p. 29-63, 1990.

LARROSA, J. B. Notas sobre a experiência e o saber da experiência. Revista Brasileira de Educação, Campinas, n. 19, p. 20-28, 2002.

LARROSA, J. B. Notas sobre narrativa e identidade (a modo de presentación). In: ABRAHÃO, Maria Helena M. B. (Org.). A aventura (auto)biográfica: teoria e empiria. Porto Alegre: EDICPUCRS, 2004. p. 11-22.

LISPECTOR, C. A quinta história. In: LISPECTOR, C. A legiāo estrangeira. São Paulo: Ática, 1977, p. 81-84.

PASSEGGI, M. C. A experiência em formação. Educação, Porto Alegre, v. 34, n. 2, p. 147-156, 2011.

PASSEGGI, M. C. Narrar é humano! Autobiografar é um processo civilizatório. In: PASSEGGI, M. C.; SILVA, V. B. (Org.). Invençôes de vidas, compreensão de itinerários e alternativas de formação. São Paulo: Cultura Acadêmica, 2010. p. 103-130.

PAULO, J. P. A. Contando uma história: ficcionando uma dissertação sobre a relaçáo entre professor e aluno. 2016. 136 f. Dissertaçáo (Mestrado em Educação Matemática) - Programa de Pós-Graduação em Educação Matemática da Universidade Estadual Paulista Júlio de Mesquita Filho, Rio Claro, 2016.

POLETTINI, A. F. F. Análise das experiências vividas determinando o desenvolvimento profissional do professor de matemática. In: BICUDO, 
Maria Aparecida V. Pesquisa em educação matemática: concepções e perspectivas. São Paulo: Editora Unesp, 1999. p. 247-261.

SKOVSMOSE, O. Cenários para investigação. Bolema, Rio, v. 13, n. 14, p. 66-91, 2000.

WHITEHEAD, J. Creating a living educational theory from questions of the kind, 'how do I improve my practice?' Cambridge Journal of Education, Cambridge, v. 19. n. 1, p. 41-52. 1989.

ZEICHNER, K. M. Uma análise crítica sobre a "reflexão" como conceito estruturante na formação docente. Educação e Sociedade, Campinas, v. 29, n. 103, p. 535-554, 2008. Disponível em: <http://www.cedes.unicamp.br>. Acesso em: 2 fev. 2015.

Recebido em: 8 fev. 2017.

Aceito em: 12 jun. 2017. 